\title{
Issues and challenges for female's participation in physical activities at secondary school level in Sargodha division
}

\begin{abstract}
This research study is an effort in line with the researches of the world to explore the magnitude and influence of general issues and challenges on female's participation in physical activities at secondary school level. The research hypotheses that there is no significant effect of issues and challenges on girl's students participation in sports and other physical activities in Sargodha division was tested. The hypothesis regarding gender difference was also tested. The population of this particular study was comprised all the Teachers, and the students in the Sargodha Division, Punjab, Pakistan. A sample of 51 selected from each district and the total sample from the whole division (3 districts) was 165. Questionnaire was used as data collection tool. The result shows that there was significant effect of issues and challenges on female's participation in sports activities and also gender difference was observed.
\end{abstract}

Keywords: sports activities, physical health, obesity, sargodha division
Volume I Issue 6 - 2017

\author{
Afshan Jabeen,' Mohibulah Khan Marwat, ${ }^{2}$ \\ Asghar Khan, ${ }^{3}$ Kashif $\mathrm{Ali}^{4}$ \\ 'Principal in Education Department Punjab, Pakistan \\ ${ }^{2}$ Director of Sports, Sports Sciences \& Physical Education, \\ Gomal University DI Khan, Pakistan \\ ${ }^{3}$ Phd Scholar, Sports Sciences \& Physical Education, Gomal \\ University DI Khan, Pakistan \\ ${ }^{4}$ Lecturer (PE) University of Sargodha, Pakistan
}

Correspondence: Afshan Jabeen, Principal in Education Department Punjab, Pakistan, Email ajmalik54@gmail.com

Received: December 18, 2017 | Published: December 22 2017

\section{Introduction}

\section{Positive impact of female's participation in physical activities}

The role of sport has always been acknowledged, as there is variation in the role of sport participation and attainment of its benefits. The general understanding of the masses about role of sport has been positive and is regarded as the human friendly engagement in everyday life. According to Cote \& Fraser $^{1}$ Sport has the potential to accomplish three important objectives which are physical health, psychosocial development and learning of motor skills. In addition to that Kilpatick et al., ${ }^{2}$ Ryska, ${ }^{3}$ Koivula ${ }^{4}$ have concluded that Sport participation has also been shown to have positive effects on physical health, psychological enhancement, stress reactivity and mental wellbeing of both genders.

Sports participation has also been positive in promoting the academics and social capabilities of the students. This concept was also supported by Khan $\mathrm{S}^{5}$ as he concluded that "Being sportsmen most of the students have shown good academic results to their credits particularly at college level". Research has supported that participation in college sports is not only beneficial for physical and mental development of the participants but can also develop the social relations of youth. This stance is supported by Khan $\mathrm{S}^{5}$ as the authors argued that the "Declining position of education can be improved through sports and games". In light of the above, it can rightly be concluded that academic achievements of the students and engagement in the sports activities are associated with each other.

Research studies by Resnick et al. ${ }^{6}$ have proved that "participation in Sport activities is more valuable in development of physical and mental health, development of the social attributes and skilldevelopment". Moreover, Relief of the mental tension, sense of well-being, acquisition of the sound health, getting entertainment and weight control are the other common benefits of participation in sport activities.

\section{Basic issues and challenges for girls' participation in physical activities}

Pakistan has been among the nations where the rate of population growth is quite high. At present Pakistan is the sixth most populous country in the world having the population of 188 million out of which $51.35 \%$ is male and 48.65 is female. (Pakistan Labour force survey 2012-13, Ministry of Planning, Development and Reforms, Population Projections for the Year 2007-2030 and Pakistan Bureau of Statistics). It has been a matter of common observation that female constitutes nearly half of the total population but despite that reality, our priorities have been changed and instead of paying attention to the promotion of female, we ignore them and have been placed them in the bottom of our priorities list. Female have generally been ignored in many occupations including providing chances for participation in sports. In the circumstances, it becomes need of the hour to provide equal chances to the female folk in many different occupations including participation in sports activities. ${ }^{7}$

A number of research studies have been conducted focusing upon different constraints(Personal, Environmental, Biological, Psychological, Social Environmental Hereditary, Peer group Access, Age, Perceived barriers Family Type of activity, Obesity, lack of time, Motivation, money and others facilities) in the way of female participation in sport. Hoden (2010), Kara \& Demirci (2010), Scott \& Mowen (2010), Stanis et al. (2010) have founded that Lack of time, lack of knowledge, family problems and lack of money and companion, are indicated as the most significant recreational constraints in the way of female participation in sport.

At most levels, women's sport attracts less funding than men's. Women make up $41 \%$ of all athletes funded through various 
programmes. At community sport level, girls' teams tend to attract less sponsorship from local businesses because they do not have large supporter bases. According to Attarzade, Sohrabi, ${ }^{8}$ Mozafari et al. ${ }^{9}$ Shores et al. ${ }^{10}$ have also concluded that Fear of assault, lack of facility, gender, race, and high entrance fee are some other factors which affect the participation of different groups of people in sport activities.

\section{The male-dominated culture of sport}

The culture of sport itself presents a problem. In the third world countries, particularly in our eastern culture, sport activities have generally been regarded as male oriented and male dominated activities. On the other hand, female are confronted with a number of problems in their way to participation in sport. Deem, ${ }^{11}$ Jackson, Henderson. ${ }^{12}$ have concluded that being dependent; it has always been difficult for women to have money to spend on recreational activities. Girls, on average, have less self- confidence than boys and rate their performance or ability more negatively than do boys. Self-confidence is also linked to competition.

The influence of parents, coaches and other adults affects girls and boys differently. Adolescent females place greater emphasis on self-comparison and comments from adults than do adolescent males, who rely more on competitive outcomes as their basis for personal judgment of physical competence. The present research study conducted to explore the issue and challenges in female's sports participation among the government college students in division Sargodha, Punjab.

\section{Statement of the problem}

Different constraints like Personal ,Environmental ,Biological, Psychological, Social Environmental Hereditary, Peer group Access, Age, Perceived Family challenges, Obesity, lack of time, Motivation, money and others facilities in the way of female participation in sport . All these factors have great influence in female's participation and promotion of sports. Keeping in view the past and current situation of sports the researcher selected the topic "Issues and challenges for female's participation in physical activities at secondary school level in division Sargodha."

\section{Objectives of the study}

Main objectives of the study were as follow:

I. To investigate the effects of issues and challenges on girls student's participation in sports and other physical activities in Sargodha division.

II. To evaluate the current scenario of women's sports and physical activities in Sargodha division.

\section{Hypothesis}

H01: There is no significant effect of issues and challenges on girl's student's participation in sports and other physical activities in Sargodha division.

$\mathrm{H} 2$ : There is no significant difference between the views of boys and girls respondents in different issues and challenges in Sargodha division.

\section{Significance of the study}

The significance of this particular study can be justified upon a number of grounds. First, let us have a look at the importance of sport in everyday life of the youth. In the present mechanic age, we assign each task of our routine life to the machines and computers which tend to make the man idle, lazy and unfit. Games and sport are the only effective means for getting recreation and satisfaction and proper use of the abundance of leisure hours and free time is nothing less than important social issue. Games and sport are the only effective means for providing frequent chances for the best use of leisure in terms of engaging us in different types of sport activities of our own choice and interest. Tension and mental worries are very common now days. Sport provides enough opportunities of getting recreation and entertainment to each member of the society without any discrimination. Sport has always yielded positive result regardless of the nature, time and type of its use and in the event of tension and mental worries sport gives the sense of freshness and entertainment to participants.

The health benefits of women's participation in physical activity and sport are now well established and globally acknowledged. Participation in sport and physical activity can prevent a number of non-communicable diseases, which account for over 60 per cent of global deaths, 66 per cent of which occur in developing countries World Health Organization. ${ }^{13}$ A player is never at pains to adjust himself in a society and he proves him/herself a useful member of the society. Play in progress can be seen in the space, on the mountains, in the plains and on the surface of water. It has been a universal activity and its importance has always been admitted. This study is going to focus upon the sport related general issues and challenges which are facing in female's participation in sports and other physical activities at secondary school level in Sargodha division, Punjab, Pakistan.

\section{Literature review}

\section{Female Participation in sports at secondary school level}

Girl's participation in sport and physical activities is quite poor in present age therefore the rate of their achievements is very poor. There are many causes of poor participation of females in sports or other recreational activities but in spite of this reality many researchers fully agree with this statement that a healthy mind lies in healthy body.

Participation in Sports and physical activities is very useful in improving the academics and social capability of the participants at college level. Khan $\mathrm{S}^{5}$ concluded that "Being a sportsperson, many of the players have shown best educational results on their credit particularly at school level". In Sargodha division, Punjab, many of the heads of institutes consider the sport activities as wastage of time and financial resources so they always show non-cooperation or very little interest in this regard. In this study the researcher also found negative and ill response of heads of female school about sports activities. They always prefer educational classes and other curricular activities to sports. They are not cooperating or facilitating the physical instructors with financial and moral support. They do not encourage the players and do not facilitate with proper coaching or sports seminars etc. Therefore the rate of female participation in sports and other activities are very poor in Sargodha division, Punjab.

Reported by Moscheny et al. about missing of proper resources like lack of proper grounds, low interest of heads or other staff, missing of sport apparatus and lack of transport faculty are main obstacles in the way of progress of female sport and physical education. According to Krouscas, there are many factors which influence the female participation in sports and games at school level like environment of class, attitude of parents and society, negative 
attitude of principal and other general teachers towards sport and games and curricular activities. Likewise According to Resnick, Jenkins, Palmer \& Spellbring, involvement in Sport and physical activities is too much helpful in enhancement of physical and mental health, build up the social characteristics and development of different skills and techniques of sports and physical activities. If the head and other staff and parents show deep interest in sports activities and give proper space to sport activities in curriculum content only then we can enhance the female participation in sports and games at school level.

\section{Methods and materials \\ Population of the study}

The population of this study comprised the physical instructor and girls students (16-20) of government girls' high school in Sargodha Division.

\section{Sample and sample size}

The researcher used multi stage sampling technique in this study. There are 5 districts in Sargodha Division, in the first stage; the researcher selected 4 girls high school from each district through convenient sampling technique. In second stage, the researcher used simple random sampling technique in which she selected 11 girls of 9th \& 10th class of each government girl's high school so the whole population of the study was 220 students and 20 physical instructors.

\section{Instrument}

The researcher developed a questionnaire and used for the data collection. The questionnaire was consisting of 10 questions. The questionnaire was put to the 20 experts from Gomal University to establish the reliability. The reliability of this questionnaire was found to be 0.89 . This questionnaire was a Likert type consisting of five options (Strongly agree, agree undecided, disagree and strongly disagree).

\section{Administration of instrument}

Questionnaire is distributed to respondents. After given time, the filled questionnaires were collected from the respondents. The researcher tries his best to explain the questions to the respondents during the distribution of questionnaire copies.

\section{Data analysis}

For the purpose of data analysis the research statistic Mean, Standard Deviation, t-statistic and Regression analysis were used. The $\mathrm{t}$-statistic is used to check the difference between two means as in the case of male and female. The regression was used to check the cause and effect relationship.

\section{Presentation and analysis of data}

\section{Test of hypothesis I: HO I}

There is no significant effect of issues and challenges on girls' student's participation in sports and other physical activities in Sargodha division. Table 1 shows the effects of major issues and challenges on sports. The $\mathrm{R}$ square is .539 which means that $54 \%$ effect on sports is due to these challenges. The $B$ is $.583(p=0.000)$ which means total 1 unit increase in issues and challenges will cause .583 unit overall increase.
Table I Effects of issues and challenges on girl's sports

\begin{tabular}{|c|c|c|c|c|c|}
\hline \multicolumn{2}{|l|}{ Model } & $\mathbf{R}$ & $\mathbf{R}$ square & $\mathbf{F}$ & Sig \\
\hline \multicolumn{2}{|c|}{ I .734(a) .539562.673.000 } & $.734(a)$ & 0.539 & 562.673 & 0 \\
\hline \multicolumn{6}{|c|}{ a, Predictors, Gb, Constant } \\
\hline \multirow[t]{2}{*}{ Model } & \multicolumn{2}{|c|}{$\begin{array}{l}\text { Unstandardized } \\
\text { coefficients }\end{array}$} & $\begin{array}{l}\text { Standardized } \\
\text { coefficients }\end{array}$ & $\mathbf{T}$ & Sig \\
\hline & B & Std. Error & Beta & & \\
\hline \multirow[t]{2}{*}{ I Gb (Constant) } & 1.595 & 0.092 & 0.734 & 17.333 & 0 \\
\hline & 0.583 & 0.025 & & 23.721 & 0 \\
\hline
\end{tabular}

Coefficients (a), Dependent Variable, collective

\section{Test of hypothesis 2}

There is no significant difference between the views of boys and girls respondents in different issues and challenges. Table 2 shows that $\mathrm{t}(482)=0.64, \mathrm{P}>0.05$ which means that there is a significant difference between male and female in issues and challenges.

Table 2 Showing gender difference in issues and challenges

\begin{tabular}{llllll}
\hline Gender & N & Mean & SD & T -value & $\mathbf{P}$-value \\
\hline Boys & 322 & 3.71 & 0.56 & 0.64 & 0.522 \\
Girls & 162 & 3.67 & 0.58 & &
\end{tabular}

\section{Discussion}

The study was conducted to assess the main issues and challenges which are influencing the girl's student's participation in sports activities at secondary level in Sargodha division, Punjab, Pakistan. The study revealed that there are some major issues which influencing the girls student's participation in sports activities. Unfortunately, during school timing there is no chance to take part in sports due to consecutive classes. The burden of Assignment and examination take most of the student's time for preparation at schools, in the preparation of test and assignment the student do not have time to participate in sports activities. Teachers also do not like the participation of students in sports activities, they think that sports activities are only leisure time activities and wastage of time and students cannot make balance between academic activities and sports activities. Most of the students only conscious about their academic activities and just focused on their home work and class in this connection, Wilson (2005) carried out a study entitled Comparing Sources of Stress in school Student Athletes and Non-Athletes. The 362 volunteer participants were take part in this study; the researcher found that athletes differed in a variety of ways from their non-athlete counterparts. Beside this, there are also some social issues which are preventing the students to participate in sports activities, students parents also consider the physical activities as a wastage of time and loss of academic career. ${ }^{14-17}$

\section{Conclusion}

The research question contributed to the aims and objectives of this study by identifying the issues and challenges to women's sports participation and then by discussing what can be done to overcome them? Through exploring these challenges from the perspective of 
women living in Sargodha division and Sports Professionals who work there, it gives a complete insight into challenges being faced in this division. The Research found that while the government has the biggest role to play in overcoming the barriers that exist, it's a combination of family, personal, culture, Education and Islamic interpretation which are the biggest challenges to participation.

\section{Acknowledgements}

None.

\section{Conflict of interest}

Authors declare that there is no conflict of interest.

\section{References}

1. Cote J, Thomas FJ. Youth involvement in sport. In: Crocker PRE, editor. Introduction to sport psychology: A Canadian perspective, Pearson Prentice Hall, Canada; 2007. p. 266-294.

2. Kilpatick M, Hebert E, Bartholomew J. College Students'Motivation for Physical Activity: Differentiating Men's and Women's Motives for Sport Participation and Exercise. J Am Coll Health. 2005;54(2):87-94.

3. Ryska TA. Sportsmanship in Young Athletes: The Role of Competitiveness, Motivational Orientation and Perceived Purposes of Sport. J Psychol. 2003;137(3):273-293.

4. Koivula N. Spot participation: Differences in motivation and participation due to gender typing. Journal of Sport Behavior. 1999;22(3):360-380.

5. Khan $\mathrm{S}$ and Khan M. Impact of Sports on academic achievement with special reference to Gomal University Dera Ismail Khan. Gomal University Journal of Research. 2004;20:1555-1163.

6. Resnick B, Palmer MH, Jenkins LS, et al. Path analysis of efficacy expectations and exercise behaviour in older adults. J Adv Nurs. 2000;31(6):1309-1315.
7. Crenshaw K. Demarginalizing the intersection of race and sex: A black feminist critique of antidiscrimination doctrine, feminist theory and antiracist politics. U Chi Legal F. 1989;1:139.

8. Attarzadeh H, Sohrabi M. Negaresh Va Gerayesh Mardom Shahr Mashhad Be Varzesh Va Faliathai Badani (Iran: Attitudes and Tendency to Exercise and Sport Activities in People of Mashhad). Olympic. 2007;15(1):38-47.

9. Mozafari A, Ahani K, Shajie A, et al. Baresi Negares Va Gerayeshn Mardom Be Varzesh Va Faliathai Badani Dar Jomhori Eslami Iran (Iran: Attitude and Tendency of People toward Physical Activity and Sport in Islamic Republic of Iran). Olympic. 2010;18(1):69-81.

10. Shores KA, Scott D, Floyd MF. Constraints to Outdoor Recreation: A Multiple Hierarchy Stratification Perspective. Leisure Sciences. 2007;29(3):227-246.

11. Deem R. All Work and no Play? The Sociology of Women and Leisure. Open University Press, Milton Keynes. England; 1986.

12. Jackson EL, Henderson KA. Gender-Based Analysis of Leisure Constraints. Leisure Sciences. 1995;17(1):31-51.

13. World Health Organization. Why move for health. Switzerland; 2007.

14. Ifedi F. Sport Participation in Canada, Culture, Tourism and the Centre for Education Statistic. Authority of the Minister responsible for Statistics Canada, Canada; 2008. p. 97.

15. Stanis SAW, Schneider IE, Pereira MA. Parks and Health: Differences in Constraints and Negotiation Strategies for Park-Based Leisure Time Physical Activity by Stage of Change. J Phys Act Health. 2010;7(2):273-284.

16. Wikipedia. Association for Intercollegiate Athletics for Women. 2014.

17. Wilson G, Pritchard M. Comparing Sources of Stress in College Student Athletes and Non-Athletes. The online Journal of Sport Psychology. 2005;7(1):1-8. 